\title{
Hepatocellular carcinoma in HCV - liver cirrhosis before and after successful DAA treatment
}

\author{
Zahari Krastev ${ }^{1}$, Deian Jelev¹, Donika Krasteva', Jordan Genov², Teodora Komitova² \\ ${ }^{1}$ Clinic of Gastroenterology, University Hospital Sv. Ivan Rilski, Medical University, Sofia 1431, Bulgaria. \\ ${ }^{2}$ Clinic of Gastroenterology, University Hospital Tsaritsa Yoanna - ISUL, Medical University, Sofia 1527, Bulgaria.
}

Correspondence to: Dr. Donika Krasteva, Clinic of Gastroenterology, University Hospital Sv. Ivan Rilski, Medical University, Sofia 1431, Bulgaria.E-mail: donika.krysteva@gmail.com

How to cite this article: Krastev Z, Jelev D, Krasteva D, Genov J, Komitova T. Hepatocellular carcinoma in HCV - liver cirrhosis before and after successful DAA treatment. Hepatoma Res 2019;5:35. http://dx.doi.org/10.20517/2394-5079.2019.02

Received: 24 Jun 2019 First Decision: 5 Aug 2019 Revised: 29 Aug 2019 Accepted: 3 Sep 2019 Published: 13 Oct 2019

Science Editor: Guangwen Cao Copy Editor: Jia-Jia Meng Production Editor: Tian Zhang

\begin{abstract}
Chronic hepatitis $\mathrm{C}$ virus (HCV) infection is a major cause of liver cirrhosis and hepatocellular carcinoma (HCC) worldwide. The recent advancement of direct-acting Antiviral Agents (DAAs) in hepatitis $C$ therapy, resulted in sustained virological response rates of over $90 \%$ in treated patients in different stages of liver fibrosis. The efficacy of DAAs treatment has also been confirmed in real-life cohorts that include subjects with decompensated cirrhosis and therefore seems a promising step to a significant reduction in the recurrence of HCC in patients who achieved complete destruction of the HCC nodules by local therapy. We present a 72-year old patient with HCVrelated liver cirrhosis who successfully responded to DAAs treatment after complete destruction of an early HCC nodule.
\end{abstract}

Keywords: Hepatocellular carcinoma, hepatitis C virus infection, Direct-acting Antiviral Agents, hepatocellular carcinoma recurrence

\section{INTRODUCTION}

The clinical implementation of direct-acting Antiviral Agents (DAAs) therapy allowed achieving over 90\% sustained virological response (SVR) rate in treated patients with chronic hepatitis C virus (HCV) infection regardless of the presence of liver cirrhosis ${ }^{[1-3]}$. The efficacy of DAAs treatment has also been confirmed in real-life cohorts that include subjects with decompensated cirrhosis and therefore seems a promising step

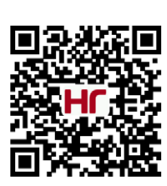


to a significant reduction in the recurrence of hepatocellular carcinoma (HCC) in patients who achieved complete destruction of the HCC nodules by local therapy ${ }^{[4-6]}$.

An unexpectedly high recurrence rate of HCC after DDAs therapy was reported by the initial studies ${ }^{[7,8]}$, however not confirmed later on ${ }^{[9,10]}$. Given the ambivalent results, any data regarding long-term DDAs therapy in the referred patient cohort are of particular interest.

\section{CASE REPORT}

A 72-year old female patient with chronic hepatitis $C$ infection and related liver cirrhosis was successfully treated with DDAs following complete destruction of HCC nodule. The patient in question has been followed-up:

- More than 18 years after liver cirrhosis was diagnosed.

- 68 months after early HCC was detected.

- 52 months after complete HCC destruction and DDAs therapy.

- 49 months after DDAs treatment.

- 46 month after achieving SRV12.

\section{HCV liver cirrhosis}

The patient presented with chronic hepatitis $\mathrm{C}$ infection (genotype $\mathrm{Ib}$ ), positive anti-HBc total antibodies, but neither positive hepatitis B surface antigen nor detectable HBV DNA and anti-HIV. No history of alcohol and drug abuse was present. She had a compensated type - II diabetes mellitus and moderate arterial hypertension.

Liver cirrhosis has been diagnosed during cholecystectomy in 2001. At that time there were no complications due to portal hypertension. The patient was declared as a primary non-responder after IFN/RBV administration in 2002, therefore received supportive treatment in the following 13 years. In that period the chronic liver disease remained compensated. The viral load remained low (HCV RNA $<800,000 \mathrm{IU} / \mathrm{mL}$ ), with normal or slightly elevated ALT $<2 \times$ upper limit of normal.

\section{HCC during HCV, before DAAs treatment}

HCC development

In September 2013 a nodule $14 \mathrm{~mm} \times 8 \mathrm{~mm}$ in size was detected in the third segment of the liver following abdominal ultrasound examination and contrast enhanced CT-scan. US-guided percutaneous biopsy diagnosed Barcelona Clinic Liver Cancer (BCLC) stage A HCC. By the time the patient had symptomatic portal hypertension with grade 2 esophageal varices and thrombocytopenia. Hence, local therapy was indicated.

\section{HCC complete destruction}

In December 2013 transarterial chemoembolization (TACE) was performed. However residual followup CT scan showed residual nodule in the third hepatic segment [Figure 1]. Therefore there sessions of radiofrequency ablation (RFA) were performed in 2014 and early 2015. CT-scan demonstrated complete ablation of the lesion after the last session, with a zone of ablation-induced necrosis $36 \mathrm{~mm} \times 47 \mathrm{~mm}$ in size [Figures 2 and 3].

\section{DDAs treatment and follow-up}

January 2015 DDAs therapy 12-week regimen with Ombitasvir, Paritaprevir/Ritonavir, Dasabuvir and Ribavirin was initiated. At week 2 HCV RNA levels became undetectable, remained so until the end of the therapy, as well as at week 12 and 24. Complete normalization of aminotransferases was observed. Transitory anemia, fatigue, jaundice due to direct hyperbilirubinemia were observed during the therapeutic period. No signs of decompensation of the chronic liver disease were present ${ }^{[1]]}$. 


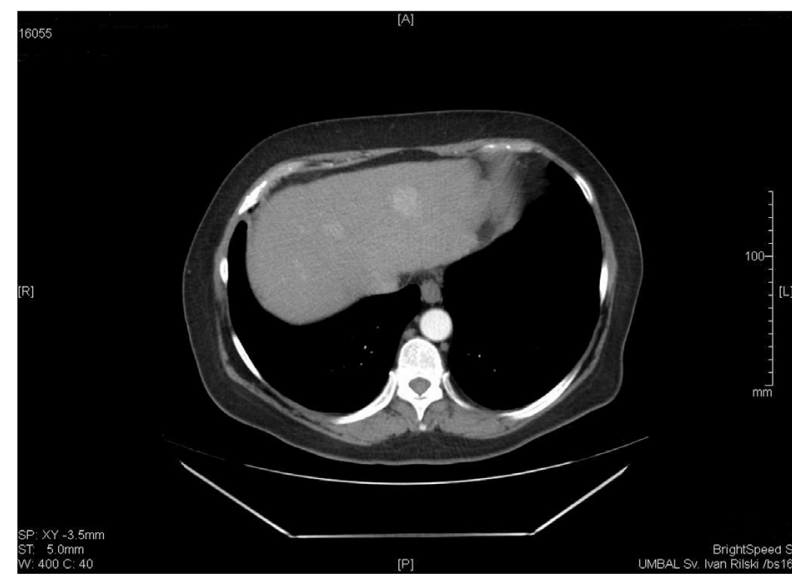

Figure 1. Contrast enhanced CT before first RFA (2014). CT: computed tomography; RFA: radiofrequency ablation

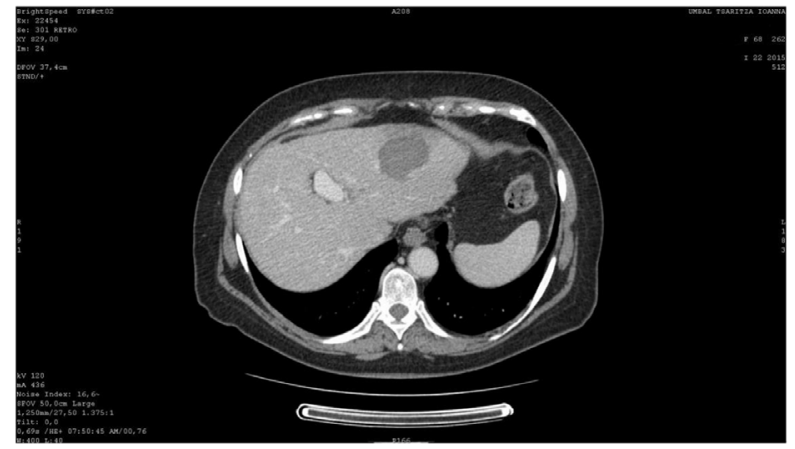

Figure 2. Contrast enhanced CT check after last RFA (2015). CT: computed tomography; RFA: radiofrequency ablation

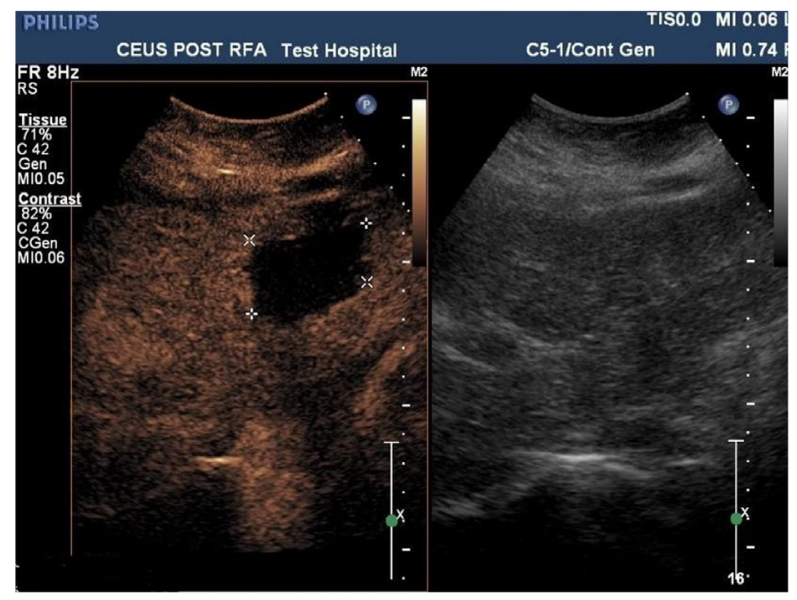

Figure 3. CEUS check after last RFA (2015). CEUS: contrast enhanced ultrasound; RFA: radiofrequency ablation

No signs of HCC recurrence were observed within the 24-week post treatment follow-up. A decrease in the alfa-fetoprotein levels ( $77 \mathrm{UI} / \mathrm{mL}$ to $4 \mathrm{UI} / \mathrm{mL}$ ) was observed by week 12 (April, 2015), remained so in the following months (July-October 2015). Contrast-enhanced ultrasound showed reduction in the size of the zone of interest to $26 \mathrm{~mm}$ (September, 2015). 


\section{HCC recurrence after SVR}

February 2018, 37 months after RFA and 34 months after SVR12, the patient was admitted for clinical follow-up. Using contrast enhanced ultrasound and contrast-enhanced computed tomography (CT)-scan a recurrent HCC nodule, $25 \mathrm{~mm} \times 20 \mathrm{~mm}$ in size, was detected in the same liver segment. The chronic liver disease was compensated, but with signs of progression of the portal hypertension with grade 3 gastroesophageal varices. Serum HCV RNA and HBV DNA were undetectable.

In March, 2018 microwave ablation and percutaneous ethanol injection were performed in the detected vital HCC nodule. Following CT-scan confirmed absence of vital tissue in the malignant nodule, with axial dimensions of the ablated zone $56 \mathrm{~mm} \times 49 \mathrm{~mm}$.

One year later, due to progression Sorafenib therapy was initiated.

\section{DISCUSSION}

The initial data that indicated increased risks of HCC recurrence after DAAs therapy have not been confirmed by subsequent studies, but the discussed problem is still a matter of debate ${ }^{[12]}$. In our case report, the late HCC recurrence is more likely to be a result of the evolution of long-lasting liver cirrhosis, rather than to the performed DAAs treatment. The discussed subject was with history of cirrhosis for more than 18 years and HCC initially occurred prior to DAAs therapy. Although, HCC was diagnosed in early stage (BCLC-A) complete destruction prior DAAs therapy was achieved by multiple sessions of local therapy (TACE and RFAs). Patients who underwent more than one HCC treatment had a higher recurrence rate than those treated only once ${ }^{[12-15]}$.

In another case, series of cirrhosis associated with HCV done in Bulgaria, more advanced HCCs were successfully treated with percutaneous thermal ablation $(n=17)$ or resection $(n=1)$. Subsequently, all patients were treated with DAA for HCV infection. HCC recidivism (local or distal intrahepatic) was observed in 13 patients (72\%) (18, personal communication). Of particular importance is that subject was anti-HBc positive. Anti-HBc has also been shown to be prognostic factor in $\mathrm{HCC}$ recurrence and recurrence free survival after curative resection ${ }^{[16,17]}$. On the other hand, HCC recurrence was detected relatively late 37 months post initial complete destruction of HCC.

The natural history of viral liver cirrhosis includes HCC development. Suppression of viral replication reduces the rate of HCC occurrence. The local therapy is successful in the early stage of HCC, but did not eliminate the risk of HCC recurrence. The new DAA therapy is very short. Some communications reported an unexpectedly high rate of HCC reoccurrence after DAA therapy, but this was not confirmed by further studies. In our case the delayed HCC recurrence might be associated not only with HCV eradication but long term disease and past HBV.

\section{DECLARATIONS}

\section{Authors' contributions}

Study concept and design, literature search, drafting the manuscript: Krastev Z, Jelev D, Krasteva D, Genov J, Komitova T

\section{Availability of data and materials}

Not applicable.

\section{Financial support and sponsorship}

None. 


\section{Conflicts of interest}

All authors declared that there no conflicts of interest.

\section{Ethical approval and consent to participate}

Not applicable.

\section{Consent for publication}

Not applicable.

\section{Copyright}

(c) The Author(s) 2019.

\section{REFERENCES}

1. Poordad F, Hezode C, Trinh R, Kowdley KV, Zeuzem S, et al. ABT-450/r-ombitasvir and dasabuvir with ribavirin for hepatitis C with cirrhosis. N Engl J Med 2014;370:1973-82.

2. Deeks ED. Ombitasvir/Paritaprevir/Ritonavir PlusDasabuvir: A Review in Chronic HCV Genotype 1 Infection. Drugs 2015;75:102738.

3. Bourlière M, Bronowicki JP, de Ledinghen V, Hézode C, Zoulim F, et al. Ledipasvir-sofosbuvir with or without ribavirin to treat patients with $\mathrm{HCV}$ genotype 1 infection and cirrhosis non-responsive to previous protease-inhibitor therapy: a randomised, doubleblind, phase 2 trial (SIRIUS). Lancet Infect Dis 2015;15:397-404.

4. Backus L, Belperio PS, Shahoumian TA, Loomis TP, Mole LA. Real-world effectiveness and predictors of sustained virological response with all-oral therapy in 21,242 hepatitis C genotype-1 patients. Antivir Ther 2017;22:481-93.

5. Sulkowski MS, Vargas HE, Di Bisceglie AM, Kuo PA, Reddy KR, et al. Effectiveness of simeprevir plus sofosbuvir, with or without ribavirin, in real-world patients with HCV Genotype 1 Infection. Gastroenterology 2015;150:419-29.

6. Foster GR, Irving WL, Cheung MCM, Walker AJ, Hudson BE, et al. Impact of direct acting antiviral therapy in patients with chronic hepatitis C and decompensated cirrhosis. J Hepatol 2016;64:1224-31.

7. Reig M, Mariño Z, Perelló C, Iñarrairaegui M, Ribeiro A, et al. Unexpected high rate of early tumor recurrence in patients with HCVrelated HCC undergoing interferon-free therapy. J Hepatol 2016;65:719-26.

8. Conti F, Buonfiglioli F, Scuteri A, Crespi C, Bolondi L, et al. Early occurrence and recurrence of hepatocellular carcinoma in HCVrelated cirrhosis treated with direct-acting antivirals. J Hepatol 2016;65:727-33.

9. Kanwal F, Kramer J, Asch SM, Chayanupatkul M, Cao Y, et al. Risk of hepatocellular cancer in HCV patients treated with directantiviral agents. Gastroenterology 2017;153:996-1005.

10. Ioannou GN, Green PK, Berry K. HCV eradication induced by direct-acting antiviral agents reduces the risk of hepatocellular carcinoma. J Hepatol 2017;68:25-32.

11. Krastev Z, Jelev D, Antonov K, Petkova T, Atanasova E, et al. Ombitasvir, paritaprevir, ritonavir, dasabuvir and ribavirin in cirrhosis after complete destruction of hepatocellular carcinoma. World J Gastroenterol 2016;22:2630-5.

12. Guarino M, Viganò L, Ponziani FR, Giannini EG, Lai Q, et al. Recurrence of hepatocellular carcinoma after direct acting antiviral treatment for hepatitis C virus infection: Literature review and risk analysis. Dig Liver Dis 2018;50:1105-14.

13. Ikeda K, Kawamura Y, Kobayashi M, Kominami Y, Fujiyama S, et al. Direct-acting antivirals decreased tumor recurrence after initial treatment of hepatitis C virus-related hepatocellular carcinoma. Dig Dis Sci 2017;62:2932-42.

14. Cabibbo G, Petta S, Calvaruso V, Cacciola I, Cannavò MR, et al. Is early recurrence of hepatocellular carcinoma in HCV cirrhotic patients affected by treatment with direct-acting antivirals? A prospective multicentre study. Aliment Pharmacol Ther 2017;46:688-95.

15. Ogawa E, Furusyo N, Nomura H, Dohmen K, Higashi N, et al. Short-term risk of hepatocellular carcinoma after hepatitis C virus eradication following direct-acting anti-viral treatment. Aliment Pharmacol Ther 2018;47:104-13.

16. Li T, Wang SK, Zhi XT, Zhou J, Dong ZR, et al. Positive HBcAb is associated with higher risk of early recurrence and poorer survival aft er curative resection of HBV-related HCC. Liver Int 2016;36:284-92.

17. Wu T, Kwok RM, Tran TT. Isolated anti-HBc: The Relevance of Hepatitis B Core Antibody-A Review of New Issues. Am J Gastroenterol 2017;112:1780-8. 